\title{
A NEW SPECIES OF SMITTIA HOLMGREN, 1869 (DIPTERA: CHIRONOMIDAE) FROM GEORGIA, USA
}

\author{
BROUGHTON A. CALDWELL ${ }^{1, *}$ and RICHARD E. JACOBSEN ${ }^{2}$ \\ 12645 Muskogee Lane, Braselton, Georgia 30517, USA and Research Associate, \\ Florida State Collection of Arthropods, Gainesville, Florida 32614, USA \\ 21828 SW Centerville Avenue, Fort White, Florida 32038, USA \\ * Corresponding author: bacaldwell@mindspring.com
}

\section{ABSTRACT}

Smittia denotata sp. nov. is described from adult males collected during winter months from two Georgia locations. The immature stages and female are unknown. The species is readily recognizable by the distinctive long, basally microtrichose, tapered anal point with rounded apex, virga consisting of two separate spine clusters, and gonostylus with crista dorsalis and curved outer thorn-like projection.

Keywords: Chironomidae, Orthocladiinae, Smittia, terrestrial, distinctive hypopygium

\section{Introduction}

The genus Smittia Holmgren, 1869 is worldwide in distribution with numerous described species, including many synonymous names. There has been no comprehensive revision of the genus. Several relatively recent publications treat various Palaearctic species (Rossaro 1988; Rossaro and Lencioni 2000; Moller Pillot 2008); an older work by Goetghebuer (1942) covered numerous species with keys to male and female adults. In a recent worldwide catalog, Ashe and O'Connor (2012) listed 83 valid species, 42 nomina dubia probably in Smittia, as well as 2 unavailable names.

Sweep netting in winter months along the floodplain of two small Georgia woodland streams yielded apparent Smittia specimens with a prominent thorn-like projection on the outer margin of the gonostylus and paired virgal spine clusters. An additional specimen was also aspirated from a home window screen along with other males identifiable as S. aterrima, not far from one of the streams. A search of species descriptions, especially with illustrations, and discussions with several colleagues indicated the Georgia specimens were apparently unique, without an available name, thus needing description. The immature stages are most likely terrestrial as are most members of the genus.

\section{Materials and Methods}

Standard morphological terminology follows Sæther (1980) and Oliver and Dillon (1989). Counts and measurements were made following Soponis (1977). Specimens were mounted in Canada balsam or Eurparal. Measurements are given in $\mu \mathrm{m}$, unless stated otherwise, and consist of the minimum, maximum and mean when 3 or more specimens were measured. The number of specimens or structures (n) measured/counted is given in parentheses when less than 5 .

The holotype and two paratypes are deposited in the William L. Peters Museum Collection of Aquatic Insects at Florida A and M University, Tallahassee, Florida, USA (part of the Florida State Collection of Arthropods). Two paratypes are in the collection of the senior author.

\section{Smittia denotata sp. nov.}

Diagnostic characters. Adult males are distinguished by an AR of 1.14-1.39, 1.28, ultimate flagellomere with strong subapical seta, about 2-4 anterior, short, slightly curved acrostichals, wing with setae on veins $R$, as well as $R_{1}$, and $R_{4+5}$, squama bare, anal point very elongate, microtrichose basally with tapered, rounded apex, superior volsella rounded, not well developed, area of inferior volsella linear, virga consisting of two separate, rather compact, elongate spine clusters, and gonostylus with curved and pointed outer thorn-like projection.

\section{Description}

Adult male $(n=5)$

Small, abdomen length about $1.5 \mathrm{~mm}$. Coloration medium/dark brown.

Head (Fig. 1): Eyes moderately pubescent, with slight dorsomesal extension, well separated, interocular distance 227-260, $247 \mu \mathrm{m}$. Temporals uniserial, inner verticals 2; outer verticals $1-3$, 2; postorbitals $2-4$, 3 . Clypeal setae $3-7,5$. Maxillary palpomere $1-5$ lengths $(\mu \mathrm{m})$ : $16-22,18 ; 25-41,32(4) ; 66-88,80 ; 52-77,68 ; 58-71,65$ (4). Antenna with AR of 1.14-1.39, 1.28, ultimate flagellomere with strong subapical seta.

Thorax (Fig. 2): Setae: lateral antepronotals 1-4, 3, very small; acrostichals anterior, up to 4 , thin and slightly curved; dorsocentrals uniserial, 8-12, 9; prealars 1-5, 4; scutellars uniserial, apparently 5-6.

Wing (Fig. 3): Setae: brachiolum 1-3, 2 (4); R 10-13, $12 ; \mathrm{R}_{1} 3-6,5 ; \mathrm{R}_{4+5} 6-11,8$. Length 1.32-1.66, $1.52 \mathrm{~mm}$. 
Legs: Fore tibial spur simple, slightly curved, 36-49, $43 \mu \mathrm{m}$ long. Mid and hind tibial spurs simple, straight: mid tibial spurs $22-27,25 \mu \mathrm{m}$ and 16-22, $21 \mu \mathrm{m}$ long; hind tibial spurs 41-55, $49 \mu \mathrm{m}$ and 19-25, $22 \mu \mathrm{m}$ long. Hind tibial comb with about 9-10, 9 spines. Lengths and ratios in Table 1.

Hypopygium (Fig. 4): Anal point very long, basally microtrichose, tapering to a narrow, rounded apex, with 3-4 setae with large sockets on each side. Gonocoxite 126-153, $141 \mu \mathrm{m}$ long; gonostylus (Figs. 5, 6) 66-82, $75 \mu \mathrm{m}$ long, outer margin with strong, curved, thorn-like projection. Crista dorsalis present (depending on orientation) but not greatly pronounced. Megaseta slightly curved with sharp apex. Superior volsella rounded, not well developed, area of inferior volsella linear. Transverse sternapodeme $74-82,79 \mu \mathrm{m}$ (4) wide; phallapodeme $38-44,41 \mu \mathrm{m}$ (4) long. Virga present, consisting of 2 compact rod-like clusters, 25-30, $26 \mu \mathrm{m}$ long.

Table 1 Smittia denotata sp. nov. leg measurements and ratios.

\begin{tabular}{|l|c|c|c|}
\hline & $\mathbf{P}_{\mathbf{1}}$ & $\mathbf{P}_{\mathbf{2}}$ & $\mathbf{P}_{\mathbf{3}}$ \\
\hline $\mathbf{f e}$ & $491-644$ & $535-688$ & $578-732$ \\
& 581 & 624 & 669 \\
\hline $\mathbf{t i}$ & $590-743$ & $562-710$ & $611-781$ \\
& 692 & 647 & 719 \\
\hline $\mathbf{t a}_{\mathbf{1}}$ & $289-382$ & $235-299$ & $322-442$ \\
& 353 & 277 & 404 \\
\hline $\mathbf{t a}_{\mathbf{2}}$ & $186-246$ & $125-164$ & $178-235$ \\
& 280 & $150(4)$ & 209 \\
\hline $\mathbf{t a}_{\mathbf{3}}$ & $120-153$ & $93-125$ & $136-180$ \\
& 141 & $110(4)$ & 164 \\
\hline ta $_{\mathbf{4}}$ & $76-98$ & $60-71$ & $76-93$ \\
& 89 & $65(4)$ & 84 \\
\hline ta $_{\mathbf{5}}$ & $55-65$ & $55-65$ & $54-65$ \\
& 62 & $60(4)$ & 62 \\
\hline LR & $0.49-0.54$ & $0.37-0.53$ & $0.53-0.60$ \\
& 0.51 & $0.43(4)$ & 0.56 \\
\hline BV & $3.10-3.28$ & $3.24-4.01$ & $3.40-4.09$ \\
& 3.18 & $3.64(4)$ & 3.60 \\
\hline SV & $3.42-3.74$ & $3.65-5.08$ & $3.21-3.69$ \\
& 3.62 & $4.63(4)$ & 3.45 \\
\hline
\end{tabular}

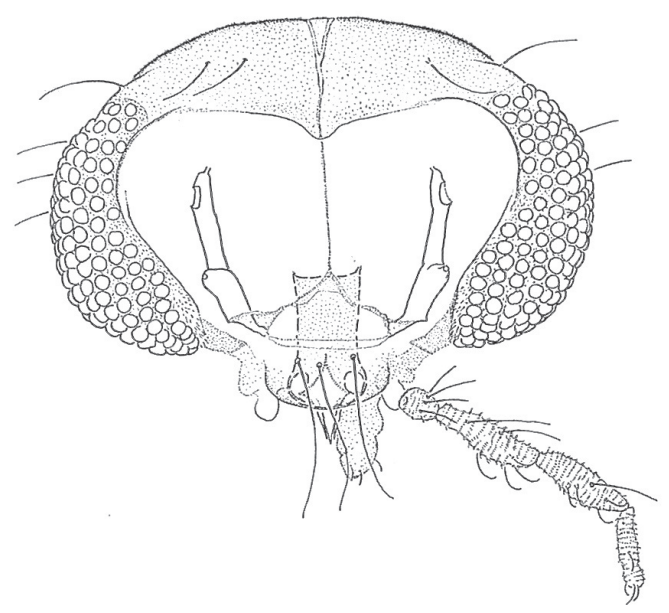

Fig. 1 Head frontal view.

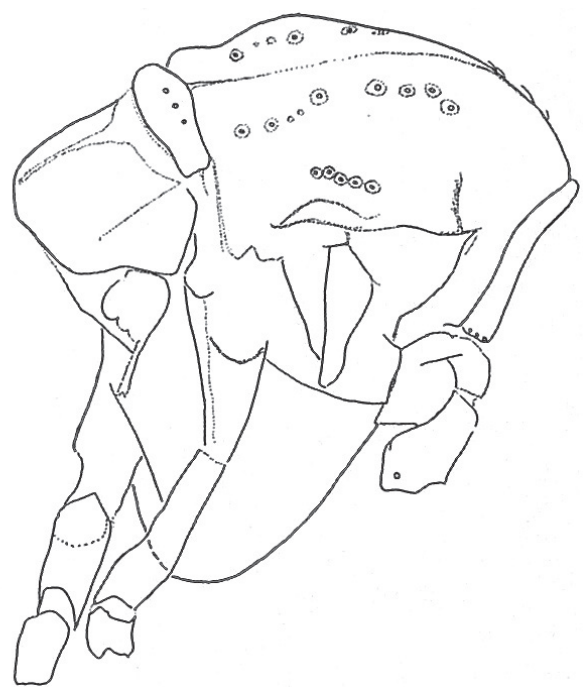

Fig. 2 Thorax dorsolateral view.

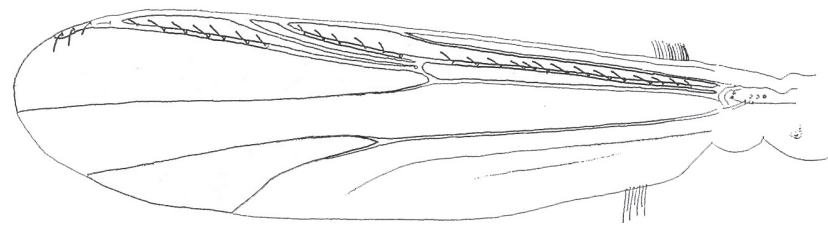

Fig. 3 Wing dorsal view.

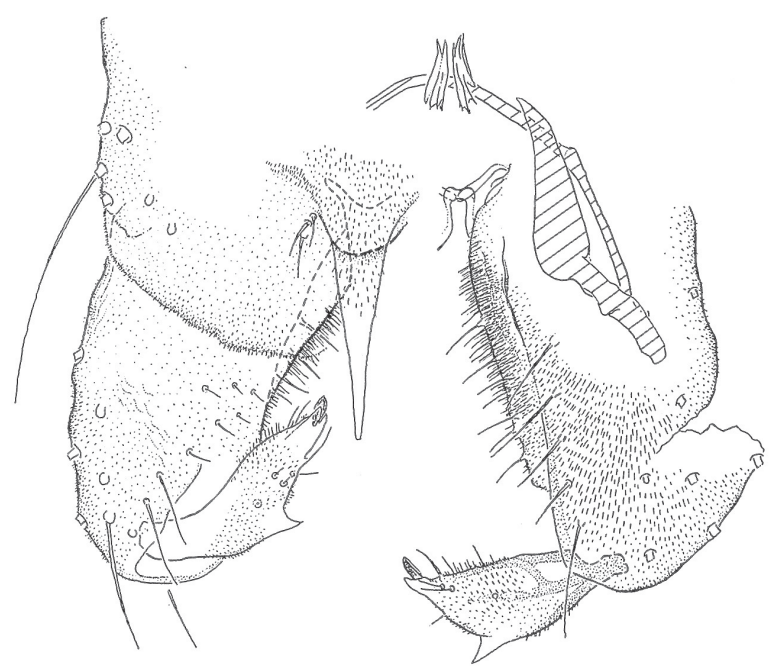

Fig. 4 Hypopygium dorsal view left ventral view right with internal structures.

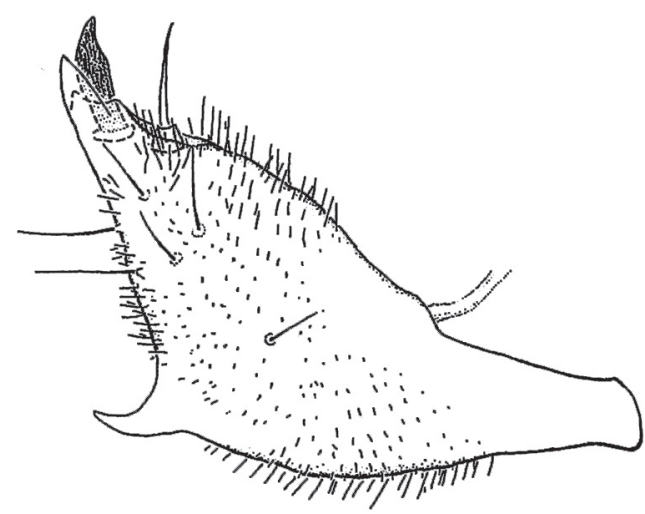

Fig. 5 Gonostylus dorsal view. 


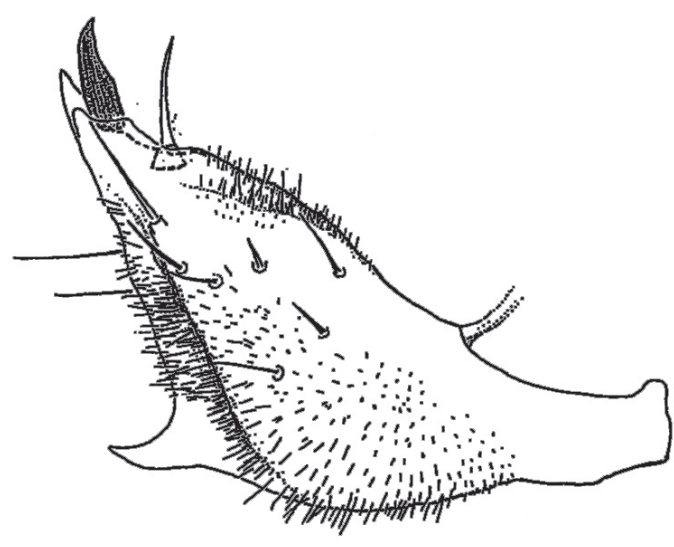

Fig. 6 Gonostylus ventral view.

Adult female and immatures. Unknown.

Etymology: The name denotata is derived from the Latin word denotatus meaning marked out or conspicuous, due to the distinctive adult male hypopygium.

Type material: Holotype male: USA, Georgia, Rockdale County, "Millrock Branch" at Haralson Mill Road, 11-I-1986, leg. B. A. Caldwell. Paratypes, 1 male, same data as holotype; 1 male, same data as holotype except Gwinnett County, on window screen, home of BAC, 2382 Rockwood Way, Stone Mountain, Georgia, 2-III-1979; 2 males, same data as holotype except Gwinnett County, unnamed tributary of Stone Mountain Creek, Rockbridge Acres Subdivision, 20-XII-1980.

\section{Discussion}

Specimens were collected by sweep netting in the floodplain of two small, wooded, Piedmont streams or aspirating (one specimen) from a home window screen near one of the streams. One stream was in a more urban residential area (Gwinnett County) while the other stream was in a more rural area (Rockdale County) with much less development. The immature stages are probably terrestrial, as are those of most members of the genus.

The new species fits best in Smittia, although differing slightly in some diagnostic features not included in Cranston et al. (1989). These features are presence of acrostichal as well as additional wing vein setae, which along with some other features have been variously noted in Caspers 1988; Rossaro 1988; Rossaro and Delettre 1992; Rossaro and Lencioni 2000; Moller Pillot 2008.

The two part virga in $S$. denotata is distinctive although not unique within the Orthocladiinae, as a two part, extremely strong and sclerotized virga is found in males of Aagaardia Sæther. The gonostylus is also distinctive in regard to the thorn-like outer projection, but unlike some taxa with similar morphology (e.g., see Prosmittia verae in Krasheninnikov and Makarchenko 2008), it differs in having a slightly produced crista dorsalis, depending on orientation. Although the apex of the gonostylus is slightly produced beyond the megaseta, a much more pronounced condition for example, is found in Smittia seppfittkaui (see Ashe and O'Connor 2012).

\section{Acknowledgements}

We thank Martin Spies, Zoologische Staatssammlung, Munich, Germany for assistance in obtaining several references and helpful suggestions and discussions to improve the manuscript.

\section{REFERENCES}

Ashe P, O'Connor JP (2012) A world catalog of Chironomidae (Diptera) Part 2, Orthocladiinae. Ir Biogeogr Soc and Natl Mus of Ir, Dublin.

Caspers N (1988) Zwei neue Smittia - Arten aus dem süddeutschen Raum. Spix Suppl 14: 175-181.

Cranston PS, Oliver DR, Sæther OA (1989) The adult males of Orthocladiinae (Diptera: Chironomidae) of the Holarctic region - Keys and diagnoses. Entomol Scand Suppl 34: 165-352.

Goetghebuer M (1940-1950) Tendipedidae (Chironomidae) F. Subfamilie Orthocladiinae. A. Die imagines. In: Lindner E (ed) Die flieg der Palaearktischen region 3(13g). E. Schweizerbart'sche Verlagsbuchhandlung, Stuttgart, pp. 1-208.

Krasheninnikov AB, Makarchenko EA (2008) Prosmittia verae sp. n. - a new chironomid species (Diptera: Chironomidae: Orthocladiinae) from the environs of Sochi Town (the Northern Caucasus). Cauc Entomol Bull 4: 359-361.

Moller Pillot HKM (2008) Identification and ecology of the genus Smittia Holmgren in the Netherlands (Diptera: Chironomidae). Tijdschr Entomol 151: 245-270.

Oliver DR, Dillon ME (1989) The adult males of Chironomidae (Diptera) of the Holarctic region - Key to subfamilies. Entomol Scand Suppl 34: 11-15.

Rossaro B (1988) Revisione del genera Smittia Holmgren (Diptera, Chironomidae), la nota (1). Atti XV Congr Naz Ital Entomol L'Aquila: 303-310.

Rossaro B, Delettre YR (1992) Description of Smittia celtica, sp. n. (Diptera: Chironomidae). Ann Soc Ent Fr (NS) 28: 365-370.

Rossaro B, Lencioni V (2000) Revision of the genus Smitta Holmgren, 1869 (Diptera Chironomidae Orthocladiinae), 2nd note. Boll Zool Agrar Bachic, ser II, 32: 97-105.

Sæther OA (1980) Glossary of chironomid morphology terminology (Diptera: Chironomidae). Entomol Scand Suppl 14: 1-51.

Soponis AR (1977) A revision of the Nearctic species of Orthocladius (Orthocladius) Van der Wulp. Mem Entomol Soc Can 102: 1-187. 